\title{
CARACTERIZAÇÃO ANATÔMICA DE CLONES COMERCIAIS DE EUCALYPTUS PARA A PRODUÇÃO DE PAPEL
}

\author{
ANATOMIC CHARACTERIZATION OF EUCALYPTUS TRADING CLONES FOR PAPER \\ PRODUCTION
}

\author{
Maiara Talgatti ${ }^{1}$, Amanda Grassmann da Silveira ${ }^{2}$, Talita Baldin ${ }^{3}$, Laura Hoffmann de Oliveira ${ }^{4}$, \\ Elio José Santini ${ }^{5}$, Débora Luana Pasa ${ }^{6}$ \\ 1, 2, 3, 4, 5, 6 Universidade Federal de Santa Maria, Santa Maria, Rio Grande do Sul, Brasil - \\ maiaratalgatti@hotmail.com, amandagrasmann@hotmail.com, talitabaldinn@gmai.com,laura- \\ hoff@hotmail.com, eliosantini@gmail.com \&deborapasa@gmail.com.
}

\begin{abstract}
RESUMO
A madeira é um recurso natural renovável que possui vantagens quando comparada a outros materiais utilizados pela indústria, o conhecimento das propriedades anatômicas do gênero Eucalyptus, tais como dimensões dos vasos e das fibras, desempenham papel fundamental em processos fisiológicos e de sustentação, e garantem o melhor aproveitamento da espécie. O objetivo do estudo foi caracterizar as madeiras de seis clones comerciais de Eucalyptus spp., sob o ponto de vista da anatomia de fibras e da densidade básica, considerando o seu aproveitamento na indústria de celulose. Os materiais de seis clones provieram de plantios comerciais com espaçamento de $2 \times 3$ metros, com 7 anos de idade. Para tanto, foram confeccionados, a partir de seis árvores de cada clone, corpos de prova para a verificação da massa específica e anatomia de fibras a partir de discos retirados na altura do peito (DAP), transformados em corpos de prova para estudos anatômicos qualitativos e quantitativos. A confecção das lâminas de macerados seguiu o método Ácido Nítrico-Acético. Para o estudo anatômico das fibras, foi observado valores do índice de Runkel menores que 1, estes são indicados para produção de papéis e considerados muito bons e bons, porém, para uma recomendação segura para esse fim, é importante que seja realizada uma análise química da sua madeira.
\end{abstract}

PALAVRAS-CHAVE: Anatomia de madeiras, Comprimento de fibras, Índices qualitativos da madeira.

\begin{abstract}
Wood is a renewable natural resource that has advantages when compared to other materials used by industry, knowledge of the anatomical properties of the genus Eucalyptus, such as vessel and fiber dimensions, play a fundamental role in physiological and sustentation processes, and guarantee the better use of the species. The objective of the study was to characterize the wood of six commercial clones of Eucalyptus spp. From the point of view of fiber anatomy and basic density, considering their use in the pulp industry. The materials of six clones came from commercial plantations with spacing of $2 \times 3$ meters, with 7 years of age. In order to do so, six specimens of each clone were prepared to verify the specific mass and anatomy of the fibers from discs taken at chest height (DAP), which were transformed into specimens for qualitative anatomical studies and quantitative. The preparation of macerated slides followed the method Nitric-Acetic Acid. For the anatomical study of the fibers, it was observed values of the Runkel index less than 1, these are indicated for paper production and considered very good and good, however, for a safe recommendation for this purpose, it is important to perform a chemical analysis.
\end{abstract}

KEYWORDS: Anatomy of woods, Fiber length, Qualitative indices of wood. 


\section{INTRODUÇÃO}

O gênero Eucalyptus vem ganhado a cada década maior destaque no cenário econômico brasileiro. Extensas áreas são cultivadas em todo o Brasil, visto que se trata um gênero de grande adaptabilidade nas mais diversas regiões do país. Com vistas a isto, os programas de melhoramento genético seguem engajados no que tange o aumento da qualidade deste gênero e a criação de novas espécies e híbridos, estes por sua vez, necessitam de estudos a fim de verificar-se a qualidade dos mesmos.

Trevisan et al. (2017) salientam a importância do conhecimento das características anatômicas da madeira como, por exemplo, as dimensões dos vasos e das fibras, as quais desempenham papel fundamental em processos fisiológicos e de sustentação. As fibras constituem o tecido básico de sustentação mecânica da madeira de folhosas. Os parâmetros considerados nos estudos de fibras compreendem o comprimento, a largura, a espessura da parede e o diâmetro do lume. Malan (1995) afirma que a espessura da parede das fibras está intimamente relacionada com a densidade da madeira, e as variações na espessura da parede entre e dentro das árvores são similares ao padrão de variação da densidade.

Conforme Neves et al. (2011), a seleção de materiais genéticos superiores, adequados às determinadas condições de sítio, torna-se fator fundamental para melhor aproveitamento de matéria prima. Corroborando, Gomide et al. (2005) salientam que as características morfológicas das fibras influenciam na qualidade do papel. Para Foelkel (2010), as dimensões das fibras exercem influência direta nas variáveis do processo de produção de celulose principalmente no grau de refino, na qualidade da pasta e, consequentemente, nas resistências físicas e mecânicas do papel. Para Castelo et al. (2017) são considerados como parâmetros nos estudos de fibras: o comprimento, a largura, a espessura da parede e o diâmetro do lume.

Com vistas a alavancar os ganhos quantitativos e qualitativos em florestas clonais faz-se de suma importância que todas as características tecnológicas das madeiras sejam aferidas. Os estudos das características anatômicas surgem como conciliadores destes ganhos, pois proporcionam índices confiáveis para estimar a qualidade das madeiras produzidas pelas empresas.

Nesta perspectiva, o objetivo deste trabalho foi caracterizar madeiras de seis clones comerciais de Eucalyptus spp., sob o ponto de vista da anatomia de fibras e da densidade básica, considerando o seu aproveitamento na indústria de celulose.

\section{MATERIAL E MÉTODOS}

\section{Seleção da matéria prima}

O material foi amostrado ao acaso, evitando-se indivíduos de bordadura, fuste tortuoso e com presença de bifurcação. Com auxílio de motosserra, foi retirada a primeira e a segunda tora de cada árvore, com aproximadamente $3 \mathrm{~m}$ de comprimento, de cada espécie/híbrido foram amostradas 6 árvores. As características das árvores selecionadas encontram-se na Tabela 1.

Tabela 1. Características das árvores selecionadas para realização da pesquisa.

\begin{tabular}{|c|c|c|c|}
\hline Clone & Local de Coleta & Espécie/Híbrido & DAP médio $(\mathrm{cm})$ \\
\hline 1005 & Telêmaco Borba-PR & $\begin{array}{c}\text { E. grandis com } E \text {. } \\
\text { camaldulensis }\end{array}$ & 17,67 \\
\hline 1006 & Paragominas -PA & $\begin{array}{c}\text { E. grandis com E. } \\
\text { urophylla }\end{array}$ & 20,93 \\
\hline 1007 & Capivari do Sul-RS & E. grandis & 30,37 \\
\hline 1008 & Capivari do Sul-RS & E. grandis & 28,22 \\
\hline 1009 & Telêmaco Borba-PR & $\begin{array}{c}\text { E. grandis com } E \text {. } \\
\text { urophylla }\end{array}$ & 22,77 \\
\hline 1010 & Telêmaco Borba-PR & $\begin{array}{c}\text { E. grandis com E. } \\
\text { urophylla }\end{array}$ & 22,15 \\
\hline
\end{tabular}

As amostras em estudo, provieram de plantios homogêneos com espaçamento $2 \mathrm{~m} \times 3 \mathrm{~m}$, com 7 anos de idade, localizados nas cidades de Capivari do Sul-RS, Paragominas-PA e Telêmaco Borba-PR.

A cidade de Capivari do Sul-RS está localizada sob as coordenadas 3008'42"S e longitude 5030'53"O, estando a uma altitude de 12 metros. De acordo com o Centro de Sensoriamento Remoto do Instituto do Meio Ambiente e dos Recursos Naturais Renováveis - CSR-IBAMA (2011), o clima da região é caracterizado como subtropical, com grande amplitude térmica, ocorrência de geadas e neve em algumas regiões durante o inverno e temperatura chegando a 35 graus no verão. A precipitação anual se situa em torno de $1.200 \mathrm{~mm}$, com pouca variação sazonal.

Já o município de Telêmaco Borba-PR, localiza-se a uma latitude $24^{\circ} 19^{\prime} 26^{\prime \prime} \mathrm{S}$ e longitude $50^{\circ} 36^{\prime} 57^{\prime \prime} \mathrm{O}$, estando a 700 metros de altitude. O clima da região, segundo a classificação de Köppen, é $\mathrm{Cfa} / \mathrm{Cfb}$, subtropical úmido transicional para temperado propriamente dito, em que a temperatura média do mês mais frio é inferior a $16^{\circ} \mathrm{C}$, com ocorrência de geada, e a temperatura média do mês mais quente é superior a $22^{\circ} \mathrm{C}$ e precipitação média anual é $1.490 \mathrm{~mm}$.

O município de Paragominas-PA situa-se a uma latitude 0259'45" S e a uma longitude 4721'10" O, 
estando a uma altitude de 90 metros. O clima é do tipo mesotérmico e úmido. A temperatura média anual é de 25ㅇ C e o regime pluviométrico é de $2.250 \mathrm{~mm}$ a 2.500 $\mathrm{mm}$ anuais, porém, o período de dezembro a junho concentra o maior volume $(80 \%)$ de precipitação (Pará, 2008).

\section{Amostragem}

Na confecção das lâminas de macerado para análise das fibras, foi selecionada uma cunha ao DAP de cada uma das seis árvores (Figura 1), totalizando seis cunhas de cada clone.

\section{Massa específica básica}

Para determinação da densidade básica foi selecionado um disco sem casca de $5,0 \mathrm{~cm}$ de espessura de cada tora na região do DAP (diâmetro à altura do peito), retirando-se duas cunhas opostas de cada disco. Assim, obtiveram-se cunhas diametrais opostas, as quais foram submersas em água até atingirem a saturação. $A$ determinação do volume saturado das cunhas realizou-se pelo método de imersão em água sobre balança analítica conforme a norma ASTM D 2395 - 93 (1997). O peso seco foi obtido após a secagem em estufa convencional de laboratório a $103 \pm 2^{\circ} \mathrm{C}$, por meio de pesagens sucessivas até que fosse aferido peso constante, de acordo com norma ASTM D 4442 - 92 (1997). De posse do volume saturado e peso seco das cunhas, efetuou-se o cálculo da massa específica básica, conforme Equação 1.

$$
M e b=M s / V u
$$

Em que: Meb = massa específica básica $\left(\right.$ g.cm- $\left.{ }^{3}\right)$; $\mathrm{Ms}=$ massa seca em estufa a $103 \pm 2^{\circ} \mathrm{C}(\mathrm{g})$; e Vu = volume saturado $\left(\mathrm{cm}^{3}\right)$.

\section{Confecção das lâminas de macerado}

De cada cunha, com auxílio de estilete, pequenas lascas do bloco de madeira selecionado foram retiradas. Para a dissociação do tecido lenhoso utilizou-se o método Ácido Nítrico-Acético (BARRICHELO et al., 1983). A solução macerante, contendo 5 partes de ácido acético para 1 de ácido nítrico, foi posteriormente diluída em água destilada, na porção 2:1. A maceração foi conduzida em banho-maria, sob ebulição durante 2 horas. Concluída a maceração, reuniu-se as células em papel filtro, sobre um funil, onde foram coloridas com safranina $1 \%$, por um período de 10 minutos.
A desidratação foi realizada pela adição de álcool comum, e posteriormente álcool absoluto, em intervalos de aproximadamente 2 minutos. Utilizou-se xilol para a diafanização e "Entellan" na montagem das lâminas de macerado. Posteriormente, foram confeccionadas cinco lâminas permanentes por espécie/híbrido que seguem a técnica tradicional. Para as avaliações referentes às fibras, foram efetuadas 25 leituras por espécie/híbrido das variáveis, comprimento, largura das fibras, largura do lume e espessura da parede, em microscópio de luz. Foram utilizadas oculares de $10 x$ e objetivas de 40x, a primeira para medir o comprimento e a segunda para medir a largura e o diâmetro do lume.

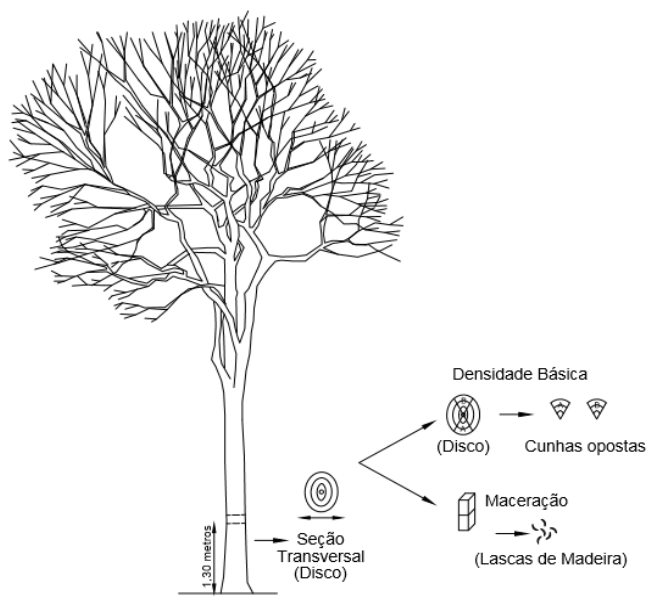

Figura 1. Ilustração da obtenção da densidade básica e lascas de madeira para a confecção de lâminas de macerado.

\section{Qualidade das fibras}

A partir dos valores médios das dimensões das fibras de cada clone, foram calculadas as relações: Fração Parede (FP), Coeficiente de Flexibilidade (CF) e Índice de Runkel (IR), de acordo com Barrichelo \& Brito (1976).

\section{Análise estatística}

A análise dos diferentes parâmetros aferidos foi realizada com auxílio do software estatístico Genes (CRUZ, 2001), por meio do delineamento inteiramente casualizado (DIC), utilizou-se a análise de variância (teste $F$ a $5 \%$ de significância), e nos casos em que a hipótese da nulidade foi rejeitada, aplicou-se o teste de Tukey (5\% de significância) para a diferenciação das médias.

\section{RESULTADOS E DISCUSSÃO}

As madeiras das espécies/híbridos de Eucaliptos, 
apresentam valores médios de massa específica básica no intervalo de 0,3930 a 0,5102 g.cm $\mathrm{cm}^{-3}$ (Tabela 2).

Tabela 2. Valores médios de massa específica básica dos clones de Eucalyptus spp.

\begin{tabular}{ccc}
\hline Clone & Espécie/Híbrido & Meb $\left(\mathbf{g} \cdot \mathbf{c m}^{-3}\right)$ \\
\hline 1005 & E. grandis com E. camaldulensis & $0,4735 \mathrm{a}( \pm 0,013)$ \\
1006 & E. grandis com E. urophylla & $0,4590 \mathrm{ab}( \pm 0,014)$ \\
1007 & E. grandis & $0,4102 \mathrm{bc}( \pm 0,006)$ \\
1008 & E. grandis & $0,3930 \mathrm{c}( \pm 0,005)$ \\
1009 & E. grandis com E. urophylla & $0,4616 \mathrm{ab}( \pm 0,006)$ \\
1010 & E. grandis com E. urophylla & $0,5102 \mathrm{a}( \pm 0,006)$ \\
\hline Média & - & 0,4512 \\
\hline
\end{tabular}

*Médias seguidas pela mesma letra na coluna não diferem entre si pelo teste de Tukey à $5 \%$ de probabilidade. Valor entre parênteses, refere-se ao desvio-padrão.

Os valores de massa específica básica, encontram-se dentro do esperado para o gênero (HILLIS, 2000). Ainda, estes valores encontram-se, de maneira geral, dentro da faixa ótima considerada para produção de celulose $(0,480$ a 0,510 g. $\mathrm{cm}^{-3}$ ) delimitada por Ribeiro \& Zani Filho (1993). Alves et al. (2011) corroboram afirmando que para a produção de papel e celulose é desejável que a madeira possua densidade uniforme, pois a velocidade de impregnação e de deslignificação dos cavacos é influenciada pela massa específica.

Os valores médios das dimensões das fibras de comprimento, largura, diâmetro do lume e espessura da parede das fibras são apresentados na Tabela 3. Pode-se observar que o clone 1010, detentor da maior massa específica básica, também apresentou maiores valores, no geral, de dimensões das fibras.

Tabela 3. Valores médios das dimensões das fibras dos clones avaliados.

\begin{tabular}{ccccc}
\hline Clone & $\begin{array}{c}\text { Comprimento } \\
(\mathbf{m m})\end{array}$ & $\begin{array}{c}\text { Largura } \\
(\boldsymbol{\mu m})\end{array}$ & $\begin{array}{c}\text { Diâmetro do } \\
\text { Lúmen }(\boldsymbol{\mu m})\end{array}$ & $\begin{array}{c}\text { Espessura da } \\
\text { parede }(\boldsymbol{\mu m})\end{array}$ \\
\hline 1005 & $0,99 \mathrm{a}$ & $16,20 \mathrm{~b}$ & $6,40 \mathrm{c}$ & $4,90 \mathrm{a}$ \\
\hline 1006 & $0,922 \mathrm{c}$ & $17,00 \mathrm{ab}$ & $9,20 \mathrm{abc}$ & $3,90 \mathrm{a}$ \\
\hline 1007 & $1,135 \mathrm{a}$ & $20,10 \mathrm{a}$ & $10,30 \mathrm{a}$ & $4,90 \mathrm{a}$ \\
\hline 1008 & $0,94 \mathrm{bc}$ & $16,20 \mathrm{~b}$ & $7,20 \mathrm{bc}$ & $4,50 \mathrm{a}$ \\
\hline 1009 & $1,106 \mathrm{a}$ & $14,50 \mathrm{ab}$ & $9,30 \mathrm{bc}$ & $4,10 \mathrm{a}$ \\
\hline 1010 & $1,086 \mathrm{ab}$ & $18,90 \mathrm{ab}$ & $8,80 \mathrm{abc}$ & $5,05 \mathrm{a}$ \\
\hline Média & 1,02 & 17,15 & 8,53 & 4,55 \\
\hline *Médias seguidas pela mesma letra na coluna não diferem entre si pelo
\end{tabular}

*Médias seguidas pela mesma letra na coluna não diferem entre si pelo teste de Tukey à $5 \%$ de probabilidade.

O diâmetro total das fibras apresentou valores médios em torno de $17,15 \mu \mathrm{m}$, sendo classificadas como estreitas, segundo classificação do lawa Committee (1989).
Estatisticamente, as mesmas apresentaram diferenças significativas entre si, com destaque ao clone 1007 que apresentou maior valor de diâmetro total, 20,10 $\mu \mathrm{m}$, seguidos das demais. A Figura 2, evidencia o macerado do material apresentando as fibras, em (a) comprimento da fibra, (b) diâmetro largura das fibras, largura do lume e espessura da parede.

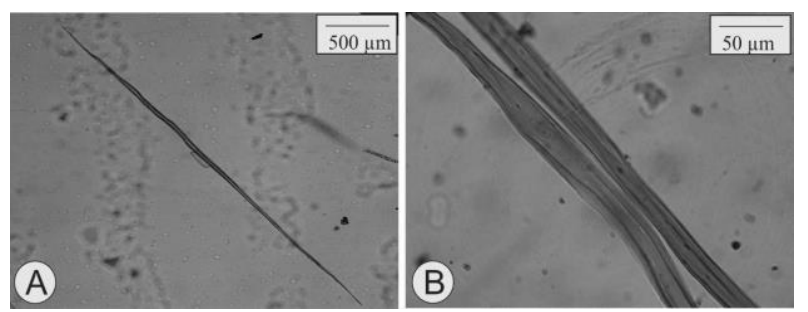

Figura 2. Macerado de material apresentando fibras, (a) comprimento da fibra, (b) diâmetro largura das fibras, largura do lume e espessura da parede.

As dimensões das fibras dos clones de Eucalyptus encontram-se no intervalo esperado para o gênero, considerado madeira de fibra curta, corroborando com os valores relatados por Motta et al. (2014) e Zanuncio et al. (2016). As fibras da madeira dos clones investigados são de baixo comprimento $(1,02 \mathrm{~mm})$, maior largura $(17,15$ $\mu \mathrm{m})$, diâmetro de lume $(8,53 \mu \mathrm{m})$ e pequena espessura da parede celular $(4,55 \mu \mathrm{m})$, características do gênero. As fibras têm função estrutural nas madeiras de folhosas e sua morfologia influenciam as propriedades da madeira (SLATER \& ENNOS, 2013).

De acordo com Barrichelo \& Brito (1976), a espessura da parede das fibras, apresentadas pelas espécies de eucaliptos, se encontram na faixa de 2,5 a $6,0 \mu \mathrm{m}$, para largura geralmente observam-se valores entre 12 a 20 $\mu \mathrm{m}$. Sendo assim, os valores verificados para espessura de parede e largura (Tabela 3) são consoantes ao esperado e observado na literatura. Ainda, Trugilho et al. (2007) ao estudarem a qualidade da madeira de clones de espécies e híbridos naturais de Eucalyptus verificaram menores valores médios de comprimento de fibras $(0,93 \mathrm{~mm})$ e de espessura da parede $(2,29 \mathrm{~mm})$, tais resultados foram atribuídos pelos autores à idade do material em estudo, cerca de 5,8 anos.

Gomide et al. (2005) relatam que fibras com parede celular mais espessa conferem maior opacidade e melhor maciez aos papéis para impressão e escrita e papéis "tissue", respectivamente, para este estudo o valor médio de espessura foi de 4,55 $\mu \mathrm{m}$. Brisola \& Demarco (2011), em caracterização anatômica das espécies: $E$. grandis, $E$. urophylla, e o híbrido Eucalyptus grandis $x$ urophylla apresentaram comprimentos médios de fibras 1.150,00 
$\mu \mathrm{m}(1,15 \mathrm{~mm}), 1.120,00 \mu \mathrm{m}(1,12 \mathrm{~mm})$ e $1.100,00 \mu \mathrm{m}$ $(1,10 \mathrm{~mm})$, respectivamente, estes valores de maneira geral, estão em concordâncias com os aferidos pelo presente estudo.

Por meio dos valores encontrados nas dimensões das fibras do material em estudo podem ser calculados coeficientes e índices, estes irão corroborar, de antemão, a compreender as características gerais da polpa e as propriedades do papel que serão produzidos com esta matéria prima. A Tabela 4 apresenta as relações entre as dimensões das fibras por meio do índice de Runkel, fração parede e coeficiente de flexibilidade.

Tabela 4. Valores médios para índice de Runkel, Fração Parede e Coeficiente de Flexibilidade das dimensões de fibras das espécies/híbridos de Eucalyptus spp.

\begin{tabular}{cccc}
\hline Clone & $\begin{array}{c}\text { Índice de } \\
\text { Runkel }\end{array}$ & $\begin{array}{c}\text { Fração Parede } \\
\text { (\%) }\end{array}$ & $\begin{array}{c}\text { Coef. de Flexibilidade } \\
\text { (\%) }\end{array}$ \\
\hline 1005 & $0,609 \mathrm{a}$ & $60,978 \mathrm{a}$ & $39,022 \mathrm{~b}$ \\
\hline 1006 & $0,473 \mathrm{~b}$ & $47,302 \mathrm{~b}$ & $52,698 \mathrm{a}$ \\
\hline 1007 & $0,467 \mathrm{~b}$ & $46,736 \mathrm{~b}$ & $53,264 \mathrm{a}$ \\
\hline 1008 & $0,569 \mathrm{ab}$ & $56,954 \mathrm{ab}$ & $43,046 \mathrm{ab}$ \\
\hline 1009 & $0,472 \mathrm{~b}$ & $47,228 \mathrm{~b}$ & $52,772 \mathrm{a}$ \\
\hline 1010 & $0,544 \mathrm{ab}$ & $54,390 \mathrm{ab}$ & $49,610 \mathrm{ab}$ \\
\hline
\end{tabular}

*Médias seguidas pela mesma letra na coluna não diferem entre si pelo teste de Tukey à $5 \%$ de probabilidade.

O clone 1005 apresentou maior valor de índice do Runkel $(0,609)$ dentre os demais, e o 1009 o menor, $(0,472)$, em relação aos avaliados. Para a fração parede os valores verificados estão na média de $52,26 \%$, indicando a rigidez das fibras, porém dentro do limite de $60 \%$ recomendado por Foelkel et al. (1978). Já coeficiente de flexibilidade estudado para estas espécies de híbridos, variou entre 39,02 e 53,26\%.

$O$ índice de Runkel avalia o grau de colapso das fibras durante o processo de produção de papel, quanto menor, maior será o colapso permitindo às fibras uma maior superfície de contato, estabelecendo maior número de ligações, resultando em um papel com maior resistência à tração e ao estouro (FLORSHEIM et al., 2009). Considerando-se os valores do Índice de Runkel (IR), estes podem ser classificados, de maneira geral como muito boas e boas, uma vez que Runkel (1952) propôs que a fibra com índice até 0,25 é considerada excelente para papel; de 0,25 a 0,50 é muito boa; de 0,50 a 1,00 é boa; de 1,00 a 2,00 regular, e acima de 2,0 não deve ser usada para papel, tendo em vista se tratar de fibras com paredes espessas ou muito espessas. Segundo Nisgoski et al.
(2012), valores altos não são desejados uma vez que a fibra se torna rígida e com maior dificuldade de acomodação e união na folha de papel. Sendo assim, os valores de IR dos clones deste estudo podem ser classificados como bons para a produção de polpa celulósica.

Os valores de fração parede estão em consonância com o aferido por Gonçalez et al. (2014) em estudo com E. grandis com E. urophylla com 8 anos e 0,510 g.cm ${ }^{-3}$ de densidade básica. De acordo com Foelkel \& Barrichelo (1975), a fração parede influencia a qualidade da celulose, valores superiores a $40 \%$ não são desejados pelas indústrias, pois não produzem celulose de boa qualidade porque as fibras são extremamente rígidas, pouco flexíveis e com dificuldades nas interligações das mesmas.

Já o coeficiente de flexibilidade apresentou valores médios menores que os verificados por Santos \& Sansígolo (2007) em estudo com clones de Eucalyptus grandis x Eucalyptus urophylla, com aproximadamente 6,5 anos. A celulose contendo fibras com menor coeficiente de flexibilidade formará um papel mais volumoso e com menores resistências, devido a maior rigidez das fibras. 0 oposto, celulose com fibras de maior coeficiente de flexibilidade formará um papel mais denso e com melhores resistências (MENEGAZZO, 2012).

\section{CONCLUSÕES}

Os resultados obtidos indicam que os clones apresentam potencial para uso múltiplo devido à variabilidade observada entre os mesmos.

As fibras que apresentam maior rigidez possuem paredes mais espessas, não sendo indicadas para produção de celulose, já os valores do índice de Runkel para produção de papel, de maneira geral, foram considerados muito bons e bons. Porém, para uma recomendação segura das espécies/híbirdos para esse fim, é importante que seja realizada uma análise química da madeira.

\section{REFERÊNCIAS}

ALVES, I.C.N. et al. Caracterização tecnológica da madeira de Eucalyptus benthamii para produção de celulose Kraft. Ciência Florestal, v.21, n.1, p.167-174, 2011.

BARRICHELO, L.E.G.; BRITO, J.O. A madeira das espécies de eucalipto como matéria-prima para a indústria de celulose e papel. Série Divulgação PRODEPEF, n.13, p.1-145, 1976.

BARRICHELO, L.E.G.; FOELKEL, C.E.B. Processo nítrico-acético para maceração de madeira. Silvicultura, v.8, n.28, p.732-733, 
1983.

BRISOLA, S.H.; DEMARCO, D. Análise anatômica do caule de Eucalyptus grandis, E. urophylla e E. grandis x urophylla: desenvolvimento da madeira e sua importância para a indústria. Scientia Florestalis, v.39, n.91, p.317-330, 2011.

BURGER, L.M.; RICHTER, H.G. Anatomia da madeira. São Paulo, 1991.

CASTELO, P.A.R. Avaliação da qualidade da madeira de Pinus taeda em diferentes sítios e espaçamentos através do método não destrutivo de ondas de tensão. 2007. 151p. (Tese de Doutorado).

COMMITTEE, I. lawa list of microscopic features for hardwood identification. lawa Journal, v.10, p.219-332, 1989.

FLORSHEIM, S.M.B. et al. Tecnologia de celulose e papel. Piracicaba: ESALQ/USP, 1975.

FOELKEL, C.E. Individualização das Fibras da Madeira do Eucalipto para a Produção de Celulose Kraft. Eucalyptus Online Book \& Newsletter, 2010. Disponível em: http://www.eucalyptus.com.br/artigos/news52_Eucalyptus_tiss ue.pdf

FOELKEL, C.E.B. et al. Eucaliptos tropicais na produção de celulose kraft. Belo Oriente, n.68, p.31, 1978.

GOMIDE, J.L. et al. Caracterização tecnológica, para produção de celulose, da nova geração de clones de Eucalyptus do Brasil. Revista Árvore, v.29, n.1, p.129-137, 2005.

GONÇALEZ, J.C. et al. Relações entre dimensões de fibras e de densidade da madeira ao longo do tronco de Eucalyptus urograndis. Scientia Forestalis, v.42, n.101, p.81-89, 2014.

HILLIS, W.E. Wood quality and growing to meet market requirements. IUFRO, 2000.

IBAMA - Instituto BRASILEIRO do meio Ambiente e dos Recursos Naturais Renováveis. Monitoramento do desmatamento nos biomas brasileiros por satélite acordo de cooperação técnica MMA/IBAMA. Monitoramento do Bioma Pampa, 2011.

MALAN, F.A. Eucalyptus improvement for lumber production. Seminário internacional de utilização da madeira de eucalipto para serraria, p.1-19, 1995.

MENEGAZZO, M.L. Características morfológicas de celuloses branqueadas de pinus e Eucalyptus em analisador óptico automático de fibras. 2012. 77p. (Dissertação de Mestrado).

MOTTA, J.P. et al. Caracterização da madeira de quatro espécies florestais. Ciência Rural, v.44, n.12, p.2186-2192, 2014.

NEVES, T.A. et al. Avaliação de clones de Eucalyptus em diferentes locais visando à produção de carvão vegetal. Pesquisa Florestal Brasileira, v.31, n.38, p.319-330, 2011.

NISGOSKI, S. et al. Características anatômicas da madeira e índices de resistência do papel de Schizolobium parahyba (Vell.)
Blake proveniente de plantio experimental. Scientia Forestalis, v.40, n.94, p.203-211, 2012.

PARÁ. Secretaria de Estado de Planejamento, Orçamento e Finanças. Estatísticas Municipais. Mesorregião Sudeste Paraense. Paragominas, 2008. Disponível em: http://www.dsr.inpe.br/sbsr2013/files/p0598.pdf.

RIBEIRO, F.A.; ZANI FILHO, J. Variação da densidade básica da madeira em espécies/procedências de Eucalyptus spp. IPEF, n.46, p.76-85, 1993.

RUNKEL, R.O.H. Pulp from tropical wood. TAAP, v.35, n.4, p.174178, 1952.

SANTOS, S.R.; SANSÍGOLO, C.A. Influência da densidade básica da madeira de clones de Eucalyptus grandis x Eucalyptus urophyllana qualidade da polpa branqueada. Ciência Florestal, v.17, n.1, p.53-63, 2007.

SLATER, D.; ENNOS, A.R. Determining the mechanical properties of hazel forks by testing their component parts. Trees, v.27, n.6, p.1515-1524, 2013.

TREVISAN, R. et al. Dimensões das fibras e sua relação com a idade de transição entre lenho juvenil e adulto de Eucalyptus grandis W. Hill ex Maiden. Ciência Florestal, v.27, n.4, p.13851393, 2017.

TRUGILHO, P.F. et al. Qualidade da madeira de clones de espécies e híbridos naturais de Eucalyptus. Scientia Forestalis, n.73, p.55-62, 2007.

FLORSHEIM, S.M.B. et al. Variação nas dimensões dos elementos anatômicos da madeira de Eucalyptus dunii aos sete anos de idade. Revista do Instituto Florestal, v.21, n.1, p.79-91, 2009.

ZANUNCIO, A.J.V. et al. Relationship between the anatomy and drying in Eucalyptus grandis $\mathrm{x}$ Eucalyptus urophylla wood. Revista Árvore, v.40, n.4, p.723-729, 2016.

Recebido em 27-06-2019 Aceito em 18-08-2019 